\title{
MDCT demonstration of jejunal angiodysplasia: an uncommon cause of lower gastrointestinal haemorrhage
}

\author{
Vandana Goel, ${ }^{1,2}$ Amit Kumar Verma, ${ }^{1}$ Sonali Sethi, ${ }^{1}$ Sunil Kumar Puri ${ }^{1}$
}

'Department of Radiology, GB Pant Hospital, New Delhi, India ${ }^{2}$ Department of Radiology, King George Medical University, Lucknow, Uttar Pradesh, India

\section{Correspondence to} Dr Amit Kumar Verma, drverma.gilbert25@gmail.com

Accepted 11 February 2014

\section{DESCRIPTION}

A 20-year-old man presented with melena for the past 3 weeks. He had no history of fever, abdominal pain, altered bowel habits, non-steroidal antiinflammatory drugs intake, petechiae or weight loss. Laboratory markers were unremarkable except for a low haemoglobin $(5.2 \mathrm{~g} / \mathrm{dL})$ for which multiple blood transfusions were given. A contrast-enhanced CT (venous phase) revealed serpiginous vascular channels along the valvulae of the proximal jejunum, although there was no active contrast extravasation seen (figures 1 and 2). In addition, there was a suspicion of malrotation of the bowel, which was confirmed preoperatively. Postoperative histopathology following segmental jejunal resection confirmed angiodysplasia of the small bowel.

Small bowel haemorrhage accounts for only $4 \%$ of all cases of gastrointestinal (GI) bleeding and of the underlying causes; angiodysplasia is a highly infrequent cause. Angiodysplasia, although the commonest vascular lesion of the GI tract involves small bowel in only $15 \%$ of cases, $77 \%$ cases involve the caecum or ascending colon. ${ }^{1}$ Most of the patients are elderly and the lesions presumably are sequel of age-related degeneration of the mucosal and submucosal blood vessels. In contrast, a congenital origin has also been implicated for lesions detected in young patients with no other attributable cause. ${ }^{2}$ Diagnosis of angiodysplasia is often challenging, although multidetector CT (MDCT), conventional angiography and capsule endoscopy may aid in their diagnosis. MDCT for GI bleeding, the best protocol is imaging without oral contrast (just water) and the scan is best performed first in the arterial phase at 30 s. The optimal management depends on the severity of haemorrhage and ranges from conservative medical therapy to endoscopic ablation and/or surgical excision. ${ }^{12}$

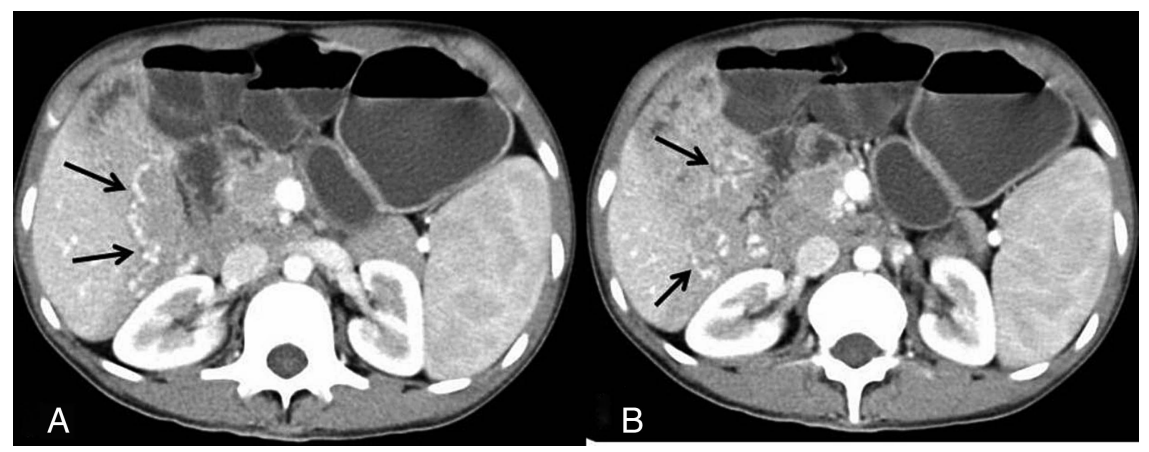

Figure 1 (A and B) Axial contrast-enhanced images in portal phase showing intramural and perienteric dilated serpiginous vascular channels in proximal jejunum (line arrow).

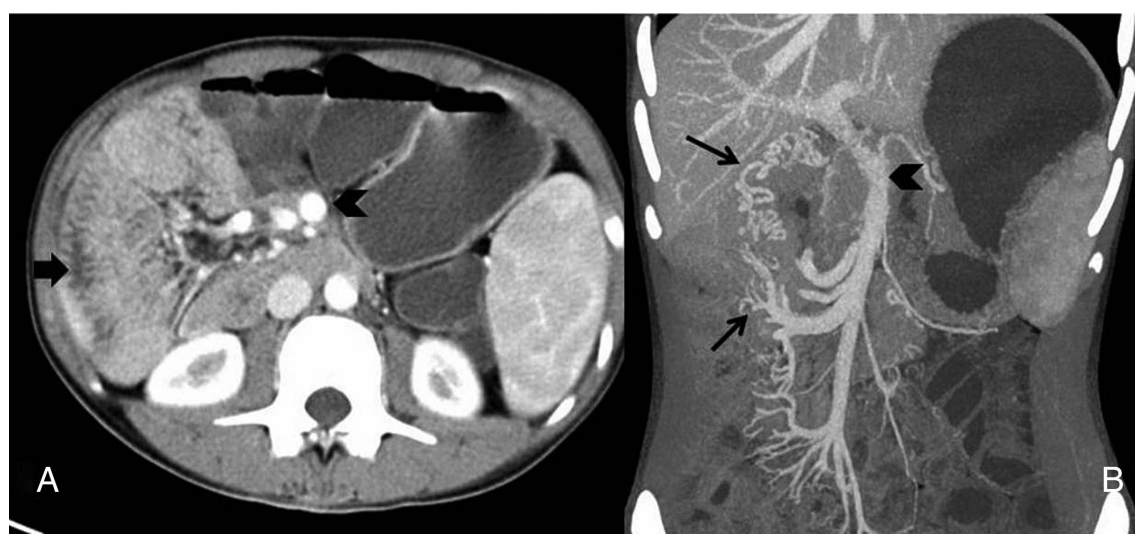
to superior mesenteric artery with jejunal loops occupying right lumbar region (bold arrow) indicating evidence of malrotation. (B) Coronal maximum intensity projection image showing a network of abnormal dilated venous channels (line arrow) in proximal jejunum draining into dilated superior mesenteric vein (arrow head). 


\section{Learning points}

- Angiodysplasia is the commonest vascular lesion of the gastrointestinal (GI) tract that usually present as $\mathrm{Gl}$ haemorrhage.

- Caecum and ascending colon are commonest segments of bowel to be involved by this disease with occasional involvement of small bowel.

- Pathological causes attributed to angiodysplasia are congenital origin in young adults and age-related vascular degeneration in elders.

- Multidetector CT, conventional angiography and capsule endoscopy are important modalities for demonstration and diagnosis of this disease.
Competing interests None.

Patient consent Obtained.

Provenance and peer review Not commissioned; externally peer reviewed.

\section{REFERENCES}

1 Al-Mehaidib A, Alnassar S, Alshamrani AS. Gastrointestinal angiodysplasia in three Saudi children. Ann Saudi Med 2009;29:223-6.

2 Uhm MS, Kim N, Nah JC, et al. Congenital angiodysplasia in a woman presenting with idiopathic jejunal varicosis on angiography. Gut Liver 2009;3:122-6.

Copyright 2014 BMJ Publishing Group. All rights reserved. For permission to reuse any of this content visit

http://group.bmj.com/group/rights-licensing/permissions.

BMJ Case Report Fellows may re-use this article for personal use and teaching without any further permission.

Become a Fellow of BMJ Case Reports today and you can:

- Submit as many cases as you like

- Enjoy fast sympathetic peer review and rapid publication of accepted articles

- Access all the published articles

- Re-use any of the published material for personal use and teaching without further permission

For information on Institutional Fellowships contact consortiasales@bmjgroup.com

Visit casereports.bmj.com for more articles like this and to become a Fellow 